\title{
Special studies program of the Pilot Health Project: West Bank and Gaza
}

Mahmoud Shaheen

Laila Nawar

Dale Huntington

Sahar Hegazi

Follow this and additional works at: https://knowledgecommons.popcouncil.org/departments_sbsr-rh

Part of the Demography, Population, and Ecology Commons, International Public Health Commons, Maternal and Child Health Commons, and the Women's Health Commons How does access to this work benefit you? Let us know!

\section{Recommended Citation}

Shaheen, Mahmoud, Laila Nawar, Dale Huntington, and Sahar Hegazi. 2001. "Special studies program of the Pilot Health Project: West Bank and Gaza," FRONTIERS Final Report. Washington, DC: Population Council. 


\section{Special Studies Program of the Pilot Health Project West Bank and Gaza}

Editor: Nancy Ali, MPH

Contributors: Mahmoud Shaheen, MD, MPH, Laila Nawar, Ph.D., Dale Huntington, Sc.D.

and Sahar Hegazi, M.A.

December 2001

This program was funded by the U.S. AGENCY FOR INTERNATIONAL DEVELOPMENT (USAID) under the terms of Cooperative Agreement Number HRN-A-00-98-00012-00 and subproject number 580513047413 . The opinions expressed herein are those of the author(s) and do not necessarily reflect the view of USAID. 


\section{ACKNOWLEDGMENTS}

Many individuals contributed to the successful implementation of the Special Studies Program. We acknowledge and thank all of the researchers who developed and implemented their studies despite the on-going political problems in the West Bank and Gaza. Their work will contribute greatly to our knowledge of reproductive health topics related to maternal and child health care and family planning (MCH/FP) in the West Bank and Gaza and will provide critical information for the development of future health and population programs. All of the service providers, women and men from the communities who consented to be interviewed and to participate in these studies also deserve special thanks.

We also acknowledge and thank the members of the Advisory Committee - Dr. Varsin Aghabekian, Dr. Aysha Al Refae, Dr. Umayia Khammesh, Ms. Najwa Rizqallah and Dr. Musallam Al-Hellow - who were instrumental in reviewing and selecting the top six research proposals that were awarded. Special thanks also go to Moushira Geziri, Merrilyn Pyle and Tawhida Khalil for editing the original final reports for each of the studies.

Finally, we acknowledge and thank both the Ministry of Health and our USAID/WB and Gaza colleagues for their support of the Special Studies Program from the onset. 


\section{CONTENTS}

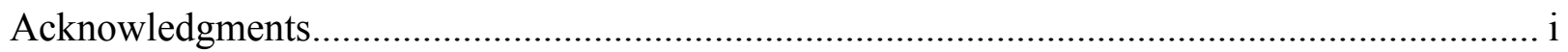

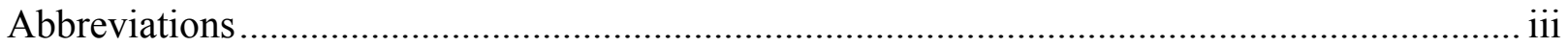

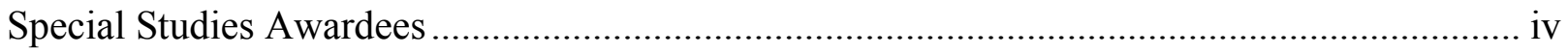

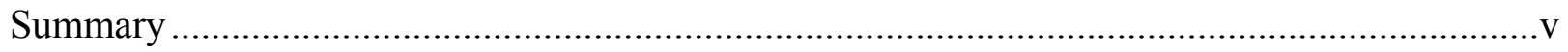

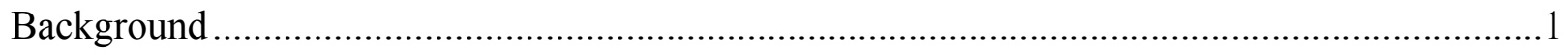

Selection and Review Process for Research Grants ....................................................

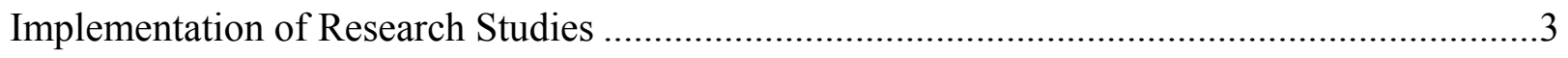

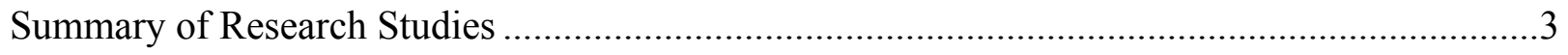

1. Male Involvement and Their Attitudes Towards Reproductive Health and Family Planning in the Gaza Strip, Palestine - Sulieman Eid, Ph.D. Candidate...........................3

2. An Evaluation of Clients' Satisfaction with the FP Programs Provided to Women at UNRWA and MOH Clinics in Gaza - Yousef Mousa, Senior Medical Officer,

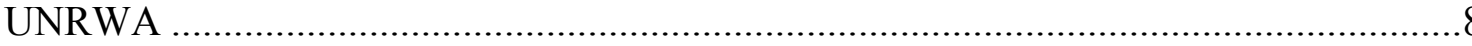

3. Relationship between Early Marriage and the Delivery of Premature Infants Nahed Eid, MPH Candidate

4. Palestinian Males' Involvement in FP - The Case Study of Al-Nussayrat Camp Mahmoud Okasha, Ph.D., Faculty, Al Azhar University

5. Assessment of Factors Affecting Non-compliance for Iron Supplementation among Anemic Pregnant Women - Ahmad Lilly, Private Pharmacist

6. Diabetes Mellitus and Pregnancy among Palestinian Women in Gaza: Risk Factors, Complications, Outcome and Quality Improvement Plan - Olfat Sha'ath, General Practitioner, MPH Candidate

Conclusion and Dissemination of Research Results. 


\section{ABBREVIATIONS}

\begin{tabular}{|c|c|}
\hline $\mathrm{ANC}$ & Antenatal Care \\
\hline CBR & Crude Birth Rate \\
\hline $\mathrm{DM}$ & Diabetes Mellitus \\
\hline FGDs & Focus Group Discussions \\
\hline FRONTIERS & Frontiers in Reproductive Health Program \\
\hline GDM & Gestational Diabetes Mellitus \\
\hline $\mathrm{Hg}$ & Hemoglobin Level \\
\hline IUDs & Intra-uterine Devices \\
\hline IUFD & Intra-uterine Fetal Death \\
\hline LBW & Low Birth Weight \\
\hline $\mathrm{MCH}$ & Maternal and Child Health \\
\hline $\mathrm{MCH} / \mathrm{FP}$ & Maternal and Child Health/Family Planning \\
\hline $\mathrm{MOH}$ & Ministry of Health \\
\hline NGOs & Non-governmental Organizations \\
\hline PC/WB\&G Office & Population Council's West Bank and Gaza Office \\
\hline PHP & Pilot Health Project \\
\hline UNRWA & $\begin{array}{l}\text { United Nations Relief and Works Agency for Palestine Refugees in the } \\
\text { Near East }\end{array}$ \\
\hline USAID & United States Agency for International Development \\
\hline WHO & World Health Organization \\
\hline
\end{tabular}




\section{SPECIAL STUDIES AWARDEES}

1. Male Involvement and Their Attitudes Towards Reproductive Health and Family Planning in the Gaza Strip-Palestine

Researcher: Sulieman Eid, Ph.D. Candidate

Study Duration: 7 months

2. An Evaluation of Clients' Satisfaction with the Family Planning Programs Provided to Women at the United Nations Relief Work Agency (UNRWA) and Ministry of Heath $(\mathrm{MOH})$ Clinics in Gaza

Researcher: Yousef Mousa, Senior Medical Officer, UNRWA

Study Duration: 8 months

3. Relationship between Early Marriage and the Delivery of Premature Infants in Selected Major Hospitals in the Gaza Strip

Researcher: Nahed Eid, MPH Candidate

Study Duration: 7 months

4. Palestinian Males' Involvement in Family Planning: The Case Study of Al-Nussayrat Camp-Gaza Strip

Researcher: Mahmoud Okasha, Ph.D., Al Azhar University

Study Duration: 8 months

5. Assessment of Factors Affecting Non-compliance for Iron Supplementation among Anemic Pregnant Women in Two Localities in Gaza Strip - Middle and Gaza Provinces Researcher: Ahmad Lilly, Private Pharmacist

Study Duration: 6 months

6. Diabetes Mellitus and Pregnancy among Palestinian Women in Gaza: Risk Factors, Complications, Outcome and Quality Improvement Plan

Researcher: Olfat Sha'at, General Practitioner, MPH Candidate

Study Duration: 6 months 


\section{SUMMARY}

The Special Studies Program was implemented as part of the Pilot Health Project in the West Bank and Gaza to provide small grants to Palestinian researchers, research organizations, and advanced graduate students to conduct research that examines critical reproductive health topics related to maternal and child health care, including family planning ( $\mathrm{MCH} / \mathrm{FP})$. The program provided opportunities for local researchers to conduct innovative research on various aspects of reproductive health that have either been understudied or are not readily available. It also supported the conduct of practical research as part of formal graduate studies.

A total of six special studies were supported under the program on a competitive basis. Priority was given to research topics that complement the activities of the Pilot Health Project. Most of the researchers were mid-level professionals from NGOs, universities or the private sector, who were also doctoral or masters candidates.

The research implemented under the Special Studies Program covered a range of topics including male involvement in reproductive health, clients' satisfaction with family planning programs, the relationship between early marriage and the delivery of premature infants, factors affecting compliance for iron supplementation, and diabetes mellitus during pregnancy.

The principal findings from the two male involvement studies indicated a positive change in the social, cultural and behavioral norms of married men and women in Palestine. The focus group and interview findings revealed that the majority of men and women in the studies considered the practice of family planning to be socially and culturally acceptable mainly for economic and health reasons. There was, however, some confusion and doubt among a few men about the "legality" of contraceptives from a religious perspective. Most of the men in the studies showed a deep understanding of the concepts and benefits of family planning and reproductive health and were familiar with several methods of contraceptives. They also indicated that they discussed family planning and reproductive issues openly with their wives and shared reproductive decisions. However, reproductive decisions are associated and affected by other factors such as the sex composition of children in families, the influence of in-laws and other family members. Both the men and women in these studies reported that they were generally satisfied with the quality of family planning services they received at UNRWA and $\mathrm{MOH}$ clinics. 
The client satisfaction study revealed that about one out of four women (23\%) expressed dissatisfaction with the quality of family planning services provided at UNRWA and $\mathrm{MOH}$ clinics. Although this is a minority, the finding does indicate that attention needs to be given to reducing waiting hours, devising mechanisms to accommodate high numbers of clients at peak hours, separating family planning clients from reproductive health patients and hiring new staff. Most clients (79.5\%) reported that they were satisfied with their service providers' skills and performance. Service providers' ability to: a) respond to clients' questions, b) gain clients' acceptance of recommended contraceptives, and c) make appointments based on clients' desire were all used to measure clients' satisfaction in this domain. Clients were least satisfied with the interpersonal communication aspects of the services (46\% were dissatisfied). Improving communication and client provider interaction services are essential to the enhancement of clients' satisfaction. This can be achieved by providing training to service providers in communication and interpersonal skills.

The study results also indicated an inverse relationship between satisfaction and age. The older the client, the less satisfied she was with the services received. Clients with intermediate levels of education were more satisfied with the services they received. Wealthier and/or highly educated clients were least satisfied with the services received. Given that continued users of contraceptives were more acquainted with the side effects of contraceptive methods and better able to cope with them, they tended to be more satisfied with the services provided. New clients were more likely not to be accustomed to side effects and may have related this to poor quality of services. Family planning services provided at Palestinian health clinics (UNRWA, MOH, NGOs) can be improved by strengthening information and counseling services and by modifying clinic hours to reduce the waiting time for clients. Continuous training of service providers on the latest contraceptive technology and guidelines for service provision will also help. This training should be reinforced by other mechanisms such as supportive supervision and follow-up home visits.

The study on the association between early marriage and premature births in the Gaza Strip indicated that women married at 18 years or younger were more likely to deliver premature infants than their older counterparts. Furthermore, data from the medical records revealed that women with higher educational levels who married later, tended to be at lower risk for delivering a premature infant. Delaying marriage among women may decrease the incidence of premature 
births and reduce community health care costs. It is also likely to enhance educational opportunities for Palestinian girls. To address the concerns related to early marriage among females, health education programs should emphasize the maternal and infant health hazards associated with early marriage among adolescent girls who are below 18 years of age. In addition, the potential complications associated with early marriage should be incorporated in medical schools' curricula. These issues should also be included in carefully designed messages that target both boys and girls in preparatory and secondary schools.

Compliance rates for iron supplementation among pregnant Palestinian women is higher than the rates determined in similar studies conducted in other developing countries. The rate of compliance for iron supplementation among pregnant women accessing ANC services at three UNRWA clinics was about 56\%. However, this rate is still below the WHO recommended level for developing countries. Most service providers, however, prescribe iron supplements only to pregnant women who have blood hemoglobin levels that are below $11 \mathrm{~g} / \mathrm{dl}$ (i.e., anemic women). Many factors were found to be associated with compliance with iron supplementation including service-related factors, socio-economic factors and the apparent quality of iron pills themselves. Although low rates of compliance can be attributed to the time consuming procedures for receiving it, the most significant factor that was directly associated with non-compliance for iron supplements was palatability. Women's knowledge of the necessity and benefits of iron supplements was modest. Universal iron supplementation for every pregnant woman attending ANC clinics and adequate supplies of high quality iron pills may improve compliance and hence lower the prevalence of anemia.

Diabetes mellitus (DM) during pregnancy is under-reported in the Gaza Strip and perhaps in all of the West Bank and Gaza. The overall prevalence of diabetes mellitus among the study sample in southern Gaza was $0.47 \%$ during 1999 and early 2000 which was below the nationally reported prevalence. Four general risk factors were considered to enhance the occurrence of DM in general and gestational diabetes (GDM) specifically. They include: maternal age of more than 30 years, positive family history of $\mathrm{DM}$, obesity (BMI $\geq 27$ ), and parity of 6 or more. The chances of women having DM during pregnancy increased greatly with the increased prevalence of the above risk factors. Data also suggest that women with a history of GDM in a previous pregnancy were at higher risk of developing GDM during their next pregnancy. 
The study findings also confirmed a significant relationship between pregnancy complications and diabetic pregnant women. The number of women reporting one or more complications (i.e., anemia, hypertension, preeclampsia, difficult labor and intra-uterine fetal death (IUFD) during the last pregnancy was significantly higher among diabetic women compared to non-diabetic women. Miscarriages, neonatal deaths and cesarean sections were also higher among diabetic women. Although the majority of diabetic pregnant women had some knowledge about the various risk factors that can cause complications during pregnancy, they were not aware of the specific risks of DM during pregnancy. Most diabetic pregnant women also registered late for antenatal care services despite having bad obstetric histories. Comprehensive screening of all pregnant women for gestational diabetes is essential to help decrease both maternal and infant morbidity and mortality. For those women who are high risk or diagnosed with diabetes during pregnancy, close observation, more frequent evaluations, and proper medical care need to be provided at the clinic level to avoid fetal and maternal complications and to decrease the possibilities of poor pregnancy outcomes. 


\section{BACKGROUND}

Scientific data regarding various aspects of reproductive health in West Bank and Gaza are not readily available. Support for practical research as part of formal graduate studies is limited. To address these issues, the Population Council implemented a Special Studies Program that provided support to Palestinian researchers, research organizations and advanced graduate students to conduct research that examines critical reproductive health topics related to maternal and child health care, including family planning (MCH/FP). The Special Studies Program is part of a larger initiative being implemented by the Population Council in the West Bank and Gaza the Pilot Health Project (PHP). The goal of the PHP is to improve the health status of Palestinian women and their children by upgrading antenatal and postpartum services in three areas in the West Bank and Gaza. The interventions of this project include the delivery of a basic package of antenatal and postpartum care services at 27 clinic sites as well as the conduct of three research studies aimed at improving the health-giving practices of providers and health-seeking behavior of families.

A total of six studies were supported under the Special Studies Program. Priority was given to research topics that complement the activities of the PHP. This final report presents an overview of the Special Studies Program and a summary of the principal findings from each study.

\section{SELECTION AND REVIEW PROCESS FOR RESEARCH GRANTS}

\section{Announcement of Special Studies Program and Call for Proposals}

An announcement of the Special Studies Program that specified guidelines for developing research proposals and information on application procedures was widely distributed in May 2000 to major research institutions and universities in the West Bank and Gaza. The announcement was also posted in the main local newspaper "Al Quds." Palestinian researchers, research organizations and advanced graduate students were encouraged to submit research proposals on critical reproductive health topics related to maternal and infant health care, including family planning, and to conduct their research in the Pilot Health Project's geographical areas. Given the relatively short duration of the grants (six months), applicants were also encouraged to use rapidly implemented qualitative research methods or secondary 
analysis of existing data sets for their studies. The average amount of funds available for successful proposals was limited to approximately $\$ 5000$ with the caveat that only exceptional and well-justified applications that exceed this amount would be considered. Applicants were given approximately one month to submit their proposals to the Population Council's West Bank and Gaza (PC/WB\&G) Office for review.

A total of 16 proposals were received, 14 in English and 2 in Arabic. The majority of proposals were received from Gaza (only three submissions came from the West Bank). Half of the proposals were submitted by graduate students who were either doctoral or masters candidates in the West Bank and Gaza. The two Arabic proposals were not accepted since they did not meet with the requirement that all proposals had to be written in English. All other proposals were reviewed by Population Council staff and determined as acceptable for the selection process.

\section{Proposal Review and Selection Process}

A multi-disciplinary advisory committee comprised of highly qualified Palestinian researchers and reproductive health experts was formulated to review and select the top six proposals. All committee members were provided with copies of the proposals and were asked to review and evaluate them according to a list of selection criteria developed by the Population Council.

A meeting was convened at the beginning of July 2000 to review and select the top six proposals. All committee members and relevant FRONTIERS staff provided comments on each proposal and graded them according to the selection criteria provided earlier. The average score for each proposal was tallied (the highest score possible was a total of 40 points) and the top six proposals were selected. The selected proposals were reviewed and discussed again carefully by the committee as a group to ensure that they deserved selection. Modifications were recommended as needed to strengthen some of the proposals selected.

Extensive revisions were made to the selected proposals by Population Council staff at all levels to further improve the quality of the proposals and to ensure they complied with the ethical requirements of the Population Council. Most of the investigators in the Special Studies Program were mid-level professionals working at NGOs, universities or in the private sector. 


\section{IMPLEMENTATION OF RESEARCH STUDIES}

Most of the research studies were initiated in January 2001 and the majority of activities were carried out during the second and third quarters of the year. Consultations between all six principal investigators and PC/WB\&G staff were conducted on a regular basis through the Special Studies Program period to provide support and monitor the progress of activities. Despite the on-going security problems and travel restrictions in the West Bank and Gaza, the majority of the researchers were able to successfully complete their studies with minor delays. Two of the principal investigators did experience some difficulties with completing data collection activities and were granted extensions. These final two studies were completed at the end of August and September 2001.

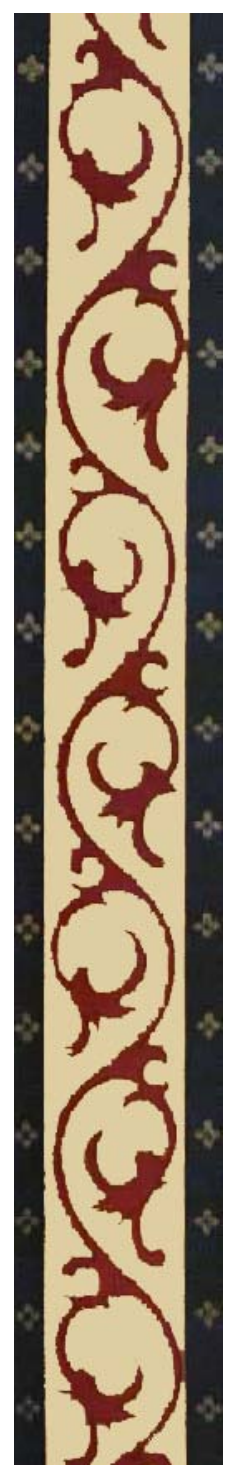

\section{SUMMARY OF RESEARCH STUDIES}

\section{Male Involvement and Their Attitudes Towards Reproductive Health and Family Planning in the Gaza Strip, Palestine - Sulieman Eid, Ph.D. Candidate}

\section{Study Background}

Until fairly recently women have been the main focus of national health programs. Although several studies have recognized men's roles in influencing women's ability to access reproductive health services and in making reproductive health decisions, most reproductive health programs targeting men focus solely on their roles as fertility regulators - promoting and disseminating the use of condoms and are still viewed only as a pathway to promoting women's health. To date the majority of male reproductive health programs fail to address men's comprehensive needs and tend to be grounded in the negative premise that men are not interested and irresponsible.

In Palestine, reproductive health and family planning decisions rest with husbands, fathers and mothers-in-laws. In addition to the fact that such decisions are also considered to be highly political and/or religious in nature. This indicates the importance and need for Palestinian men to be appropriately approached, educated 
and informed about reproductive health and family planning. Family planning has also become a priority for the $\mathrm{MOH}$ and is offered through primary health care services at the United Nations Relief and Works Agency for Palestine Refugees in the Near East (UNRWA), governmental and NGO clinics. Given the above and the fact that only a few studies have been conducted that explore men's acceptance and support of reproductive health principles and services in Palestine, the proposed study was developed to meet the following objectives:

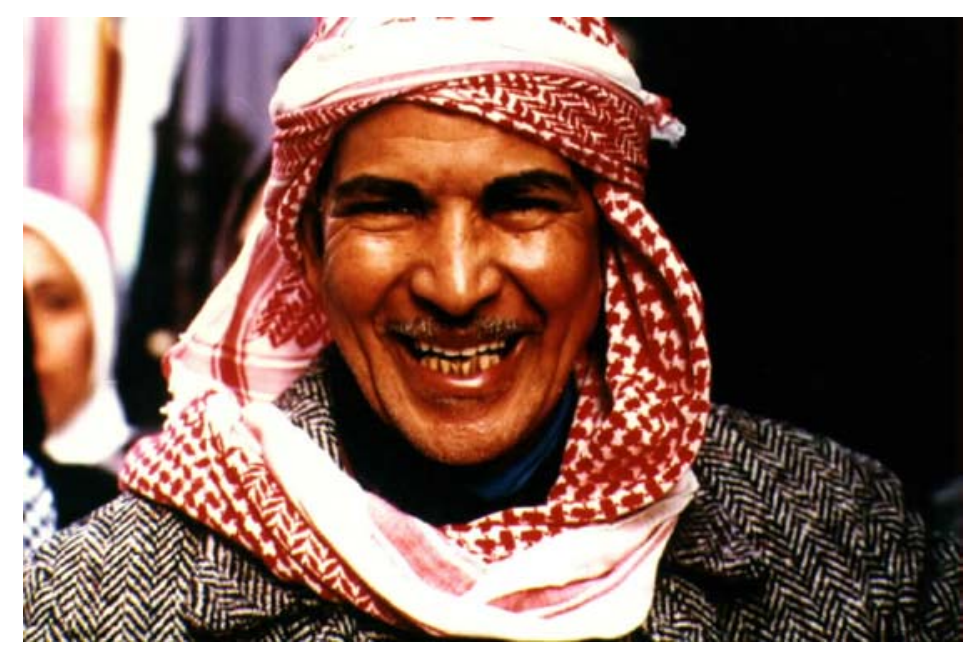

a) Identify the degree of men's participation in current reproductive health and family planning programs.

b) Assess males' perceptions and attitudes towards reproductive health as well as barriers that hinder their involvement.

c) Determine the desirable level of male participation from the point of view of their partners and health care providers.

The operational definition for male involvement used in this study is men's willingness to discuss, use, support and/or approve of family planning methods.

\section{Study Methodology}

The grant awarded through the Special Studies Program only supported part of the overall research activities for this study - mainly the conduct of focus group discussions (FGDs) that collected relevant descriptive data. The overall cross-sectional study also includes the conduct of in-depth interviews and clinic observations that were supported using other resources and are reported on elsewhere. A total of twenty FGDs were conducted as part of the Special Studies Program. Selection criteria used for participation in the FGDs included all married women accessing primary health care services at study clinics with infants aged 9 to 15 months old, and all married men accessing primary health care services at the study clinics. Sixty-seven women and 53 men were selected to participate in the FGDs. 
Gaza was chosen as the setting for this research because it is a densely populated area (347 inhabitants per one square kilometer) with an average Crude Birth Rate (CBR) of 33.6 per thousand. A total of four clinics - two MOH and two UNRWA clinics - were selected as the study sites. The $\mathrm{MOH}$ and UNRWA are the main providers of reproductive and family planning services in the Gaza Strip.

\section{Study Findings}

\section{a. Male attitudes towards reproductive health and family planning}

The majority of participants had an in-depth understanding of the concepts of reproductive health and family planning. However, many were confused
"Family planning means a lot; it means social, health and economic stability. These, by way or another, have great impact on the family and the entire community..." (married man, age 32 )

"It is a civilized way to plan our future, and 1 wonder why some religious figures say it is against Islam. I hope all religious figures will agree and give clear statements legalizing the practice of family planning." (married woman, age 22)

'Family planning which aims at 'planning' is socially and religiously acceptable.... The problem is when one limits the number of children, which is unacceptable in the Islamic faith." (married woman, 8 children)

"In my opinion this subject has many dimensions including social, religious and cultural aspects.... We have to support mothers seeking family planning, within a religious framework, in order to allow them to enlarge the space between pregnancies." (married man, age 30)

about the distinction between family planning and birth spacing, particularly from a religious perspective.

\section{b. Social and cultural acceptability}

The majority of men believed that reproductive health services, including family planning services, are socially and culturally acceptable. However, the exact position of men was less clear, and they seem to be primarily concerned about the sex of the health

\footnotetext{
"No matter how high the family income is, one can still see the difference in the quality of life between those who have many children and those who plan their families, in terms of education, health, housing and the different aspects of life." (newly married man, age 22)

"With the present high rate of unemployment, I wonder how big families in the camps manage. I think those with small families can manage with less expenses." (married unemployed man, age 42)

"I am 30 years old. I am completely against the concept of family planning ... and reject the whole idea." (infertile woman)

"I have four children and a big problem with my mother who wants more children. I am a regular employee with very limited income. I have to make my own decisions. It is not just about whether there is enough bread to feed the family; it is more than that." (married man, age 31)
}

providers performing such services. In general, however, they expressed support for their wives to practice family planning and promote their reproductive health. In order to capitalize on this 
positive attitude and draw men more into the family planning and reproductive health picture, a socially and culturally sensitive approach for addressing men about these issues is needed.

\section{c. Couples' opinions of existing services and their recommendations}

Both male and

female participants in the

focus groups discussions

were highly satisfied with

the family planning

services they received from

UNRWA and MOH clinics.

They did, however,
"I can understand that all participants are fully satisfied with the existing services, especially when they are offered by female providers." (married male physician, age 47)

"In fact, the services offered by UNRWA are excellent. Since my wife tried these services, she has been very happy with them. She brought home many articles and educational materials that provide information not only for her, but also for the entire family." (married male school teacher, age 39)

"The existing services are very good and I support my wife using them." (married man, three children)

highlight the problems with long waiting hours and, sometimes, the shortage of supplies.

\begin{abstract}
"As a conservative community, we do not provide information about reproductive health issues to children.... $A$ lot of the information we receive does not match our cultural values. I believe though, that some communities have deep understanding of the concepts of reproductive health and family planning, such as young parents." (married woman, age 45)

"There are many sources of information that highlight the benefits of family planning, but the most important indication of its importance is reflected in the surrounding environment: families with a large number of children and very limited socio-economic resources to support its members." (unemployed married man, age 37)
\end{abstract}

\section{d. Sources of reproductive health and family} planning information

The socio-political situation, which favors large families and a large number of children, generally influences the level of dissemination of information on family planning and reproductive health. Key sources of information include the family, schools, peer groups, the radio and the television.

e. Couples' discussions

of reproductive health and family planning matters

All of the male participants in

the FGDs reported that they speak openly with their wives about reproductive health and family planning matters.

\section{f. Preference for male children}

The focus group discussions also indicated that having male children is of great importance to Palestinian families.
"Yes, we discuss this subject in a democratic way with our wives. I believe this subject is one of our top priorities." (married man, age 24)

"Yes, in fact we discuss this topic openly all the time. This depends on the level of awareness and the couple's understanding of the concept of family planning and why they want to practice it. There is no need to be shy..." (married female nurse, age 28 , three children)

"Well, yes, it is discussed openly between us, but as you know, the final decision rests with the man." (married woman, age 29) 


\section{Discussion and Recommendations}

- Health education programs that target young men to bridge the gap between their attitudes and beliefs and actual practice need to be designed and implemented. These programs should emphasize that reproductive health and family planning services are needed not only to enhance women's health, but also to promote the health and welfare of the community as a whole.

- Health education should not be limited to married couples, but should also be provided to extended family members, especially mothers-in-laws and other influential family members.

- Religious leaders should be oriented and involved in discussions related to the concepts of reproductive health and family planning at the community level. There should also be consensus among themselves about the interpretation of these topics from the religious context.

- Mass media, particularly radio and TV, should be used to promote knowledge and favorable attitudes towards reproductive health and family planning. Parents should also be encouraged to discuss these issues with their children.

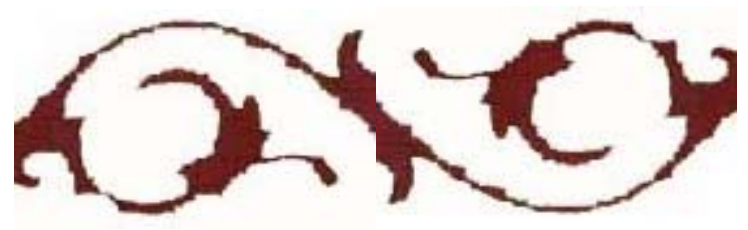




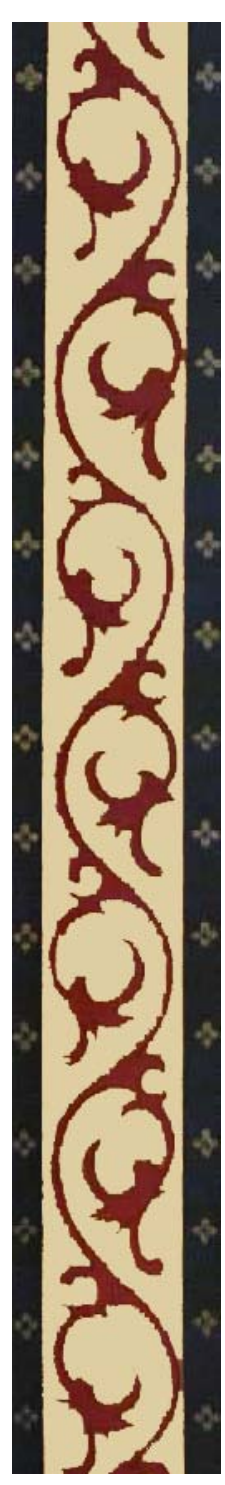

2. An Evaluation of Clients' Satisfaction with Family Planning Programs Provided to Women at United Nations Relief Work Agency (UNRWA) and Ministry of Health (MOH) Clinics in Gaza - Yousef Mousa, Senior Medical Officer, UNRWA

\section{Study Background}

There is an increasing trend towards involving consumers in the process of evaluating the quality of care of health services by measuring their satisfaction with the services. However, this is not an easy undertaking. Previous studies on clients' satisfaction with health care services have shown that satisfaction is a multidimensional and complex concept. Clients' perceptions may be influenced by expectations, prior experience and reliance on the opinion/experience of others. Studies that attempted to measure satisfaction as related to specific and salient characteristics of a service also suffer limitations because the questions posed do not always capture patients' complex ideas and beliefs.

A review of existing literature indicated that most studies on client satisfaction have several limitations. Most of the studies reviewed: 1) neglected to explore the relationship between client satisfaction and socio-demographic variables (such as gender, ethnic origin and class); 2) did not examine specific aspects and quality of services; 3) focused more on clients' satisfaction rather than their dissatisfaction with a health service; 4) assumed that there was a direct relationship between expectations and satisfaction; and 5) used quantitative scales that are accurate but do not capture insights.

In 1993, after the signing of the peace accords with Israel, the Palestinian Authority became another key provider of health services in Gaza. Despite the multiple health sectors (including NGOs and the private sector), the government's large allocation of resources towards health care and the marked increase in the number of married women using contraceptives, the quality of family planning services provided at Palestinian health facilities has been questioned and debated. Many stakeholders have stressed the need to evaluate it.

This research study funded by the Population Council and supported by UNRWA and the Palestinian $\mathrm{MOH}$ is a new initiative in Palestine. It assesses clients' satisfaction with family planning services provided by UNRWA and the MOH in the Gaza Strip, with the aim of presenting relevant policy recommendations for improving the quality of family planning 
services. Gaza was selected as the site for this study because it has a rapid population growth impacting almost every aspect of life and the highest concentration of refugees - 79 percent of its population consists of refugees who receive services from UNRWA.

\section{Study Methodology}

Six UNRWA and MOH clinics (three from each organization) were randomly selected as the sites for this study. A total of 377 new and continuing contraceptive users receiving family planning services at these clinics were interviewed through home visits by trained interviewers. A Likert scale was used to measure the respondents' subjective appraisals of key service delivery characteristics, including: an assessment of the provider's technical and interpersonal skills, the amenities of the care-giving environment, and the personal attention and respect accorded to clients. Statements were read out to clients and they were asked to score them on a four-point scale. The questionnaire also included several open-ended questions to solicit additional information about the quality of care received by clients.

The study's inclusion criterion was all clients currently using family planning services from UNRWA and $\mathrm{MOH}$ clinics. Two important groups are not represented in the study: those who dropped out of the clinics, and those who refused to participate in the study. The inclusion of these two groups may have reflected dissatisfaction with the quality of services and would have been important to the study. The study's overall response rate was 87.3 percent.

\section{Study Findings}

\section{a. Socio-economic background}

The majority of women included in the study were young (mean age 30.4 years, median age 30 years). The largest age category of women interviewed was 26 to 35 years old, representing about half $(52.3 \%)$ of the study population. About 70 percent of the women interviewed lived in towns, 22.5 percent inside refugee camps and 7 percent in villages. The study revealed differences in the preferred method of contraception based on residence. Clients residing inside refugee camps preferred the IUD (64.4\%) while those residing outside refugee camps preferred oral contraceptive pills. About two-thirds (61.4\%) of the women had five or less deliveries and the remaining women had six or more deliveries (38.6\%). 


\section{b. Contraceptive prevalence}

Almost 60 percent of the women interviewed (197 new family planning acceptors) used modern family planning methods and 41.2 percent (132 clients) are continuing users. IUDs and oral contraceptive pills are the most preferred methods of contraception in the study $(49.2 \%$ use IUDs, $28.3 \%$ use oral contraceptive pills, $17 \%$ use condoms and 5.5\% used other methods). The IUD is the most popular method of contraception at UNRWA clinics $(64 \%)$. Around 40 percent of the clients who access services at $\mathrm{MOH}$ clinics use oral contraceptive pills.

Most women reported that the decision to select and use a contraceptive method was jointly made with their husbands (about $83 \%$ ). Only 12 percent of the women interviewed reported that they made

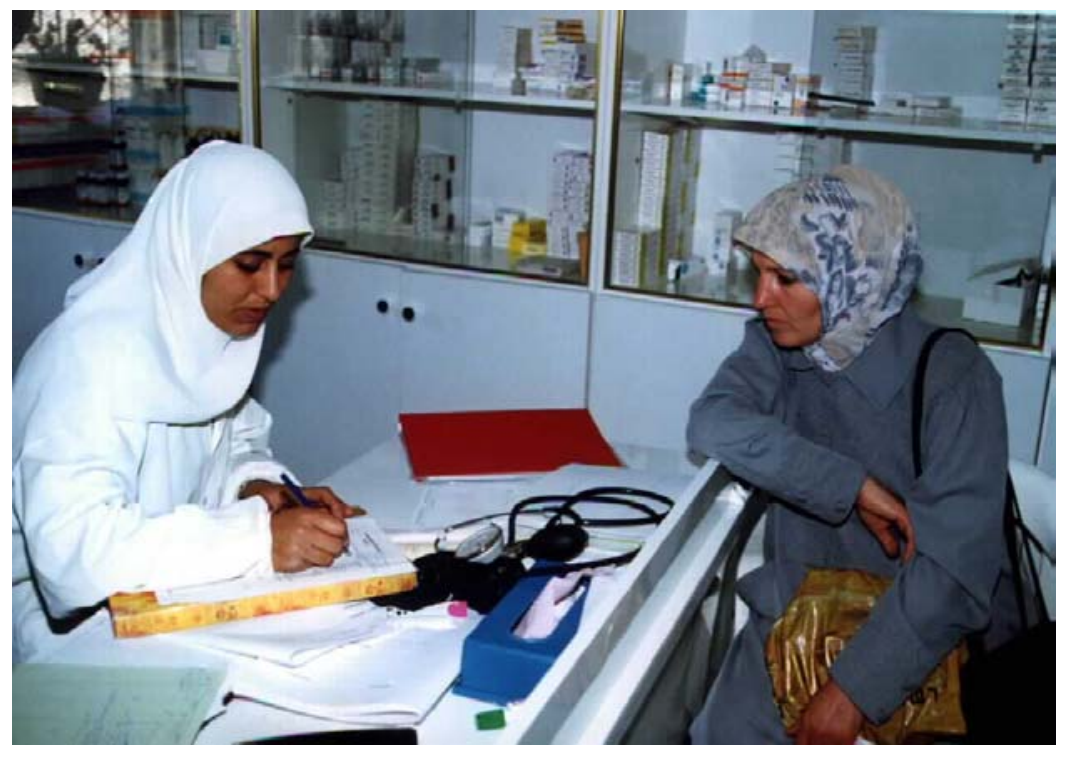
the decision to use a contraceptive method independently.

\section{c. Level of satisfaction with services}

About three-fourths $(72 \%)$ of the respondents reported being satisfied with the family planning services they received. Client satisfaction with the information and counseling services received at the clinics was particularly high. However, communication and client provider interaction received the lowest scores in terms of satisfaction. The clients' satisfaction scale used for this study measured five domains of the services offered:

- Attitudes and expectations

- Information and counseling

- Communications and interactions

- Mechanisms of care

- Delivery of care 


\section{d. Variables affecting satisfaction}

\section{Demographic variables}

- Age groups: The study showed an inverse relationship between level of satisfaction and age of users: the level of satisfaction decreased as age increased. The highest level of satisfaction with services was found among women who were 25 years old or younger. This age group was satisfied with the expectations and attitudes of care, information and counseling, and the mechanisms of care. These findings were statistically significant.

- Education: Clients with 7-12 years of education were generally more satisfied with family planning methods and services than other groups (6 years or less or more than 12 years).

- Residence: In general, clients living inside the refugee camps are more satisfied with the care received than those living outside them. Satisfaction scores varied according to the provinces where women live. For example, women residing in North Gaza are the most satisfied clients (particularly with regards to attitudes and expectations) and women residing in the middle-zone of Gaza were the least satisfied.

- Employment: Unemployed women (90.3\% of the family planning users) were more satisfied with services than those who were employed (9.7\%). These women were satisfied with all of the domains of family planning services, particularly information and counseling and the delivery of care.

- Economic status: The study indicated that as income levels increase, satisfaction with family planning services decrease. Poor women were the most satisfied of all economic groups.

\section{Method-related variables}

- Method of contraceptive used: The most satisfied clients in the study were those women whose husbands used condoms. Women using intra-uterine devices (IUDs) were satisfied with attitudes of service providers and with the expectations of services provided. Those using the pill were satisfied with the information and counseling they received and were also satisfied with the mechanism used at the clinic to deliver this service. 
- Continuing clients versus new acceptors: Clients who have been using contraceptives for some time through UNRWA and MOH clinics were more satisfied with family planning services provided compared to new acceptors (those using the services for the first time). They were satisfied with all domains of the services - particularly with regard to attitudes and expectations.

\section{Service-related variables}

- Parity: Low parity women were more satisfied with the family planning services they received than high parity women.

- Service provider: UNRWA clients were generally more satisfied with the skills and practices of their service providers than $\mathrm{MOH}$ clients.

- Confidentiality of service: The majority of women (about 98\%) reported that family planning services were handled with utmost confidentiality. Only six women mentioned that their privacy had been violated.

\section{Discussion and Program Implications}

\section{Client flow and clinic operations}

About one out of four women (23\%) expressed dissatisfaction with the quality of services provided at the clinics. Although this is a minority, the finding does indicate that attention needs to be given to reducing waiting hours, devising mechanisms to accommodate high numbers of clients at peak hours, and hiring new staff. Most clients who were interviewed (79.5\%) reported that they were satisfied with their service providers' skills and performances. Service providers' ability to: a) respond to clients' questions, b) gain clients' acceptance of recommended contraceptives, and c) make appointments based on clients' desire were all used to measure clients' satisfaction in this domain.

\section{Communication and client-provider interaction}

Clients were least satisfied with the interpersonal communication aspects of the services (46\% were dissatisfied). The variables examined to determine the above finding included listening to clients, inaccurate or incomplete explanations of services, respect for clients' privacy, and long waiting periods. They all did not meet the acceptable performance standards. 
Improving communication and client provider interaction services are essential to the enhancement of clients' satisfaction. This can be achieved by providing training courses for service providers in communication and interpersonal skills. Clients did, however, express a high level of satisfaction with the counseling and information they received at the clinics (81\%). This indicates that they were making informed choices about available family planning methods and trusted their service providers. The variables examined to determine counseling and information levels included appropriate health education, accurate information about family planning methods and the availability of informational booklets.

\section{Couples' decision to use modern contraceptive methods}

The study's finding that decisions to use family planning methods are made mostly by couples without intervention from others (about 83\%) is mainly due to the fact that the majority of clients included in the study live in nuclear families, thus minimizing the role of members of the extended family in influencing their decisions.

\section{Effect of socio-economic variables on level of satisfaction}

- Age: The study findings indicated an inverse relationship between satisfaction and age. The older the client, the less satisfied she was with the services received.

- Residence: Clients from within refugee camps in general were more satisfied with family planning services they received than those residing outside of the camps. This may be attributed to the homogeneity of the social class within the camps, and consequently having similar expectations. UNRWA clients were also generally more satisfied with the services received compared with $\mathrm{MOH}$ clients. This may be due to the fact that UNRWA has been serving the camp populations for a long time and has developed strong bonds with the people. Moreover, UNRWA clinics are conveniently located to most clients and the services they offer are free of charge.

- Education and economic status: Clients with intermediate levels of education were more satisfied with the services they received. Highly educated clients were least satisfied with the services offered. Similarly wealthier clients expressed a lower level of satisfaction with services. Poor patients had lower expectations in general. 
Contraceptive use : Continuing users of contraceptives are more acquainted with the side effects of contraceptive methods and are better able to cope with them. Therefore, they tend to be more satisfied with the services provided as opposed to new clients who are not accustomed to side effects and may relate it to poor quality of services.

\section{Recommendations}

Family planning services provided at Palestinian health clinics (UNRWA, MOH, NGOs) can be improved with the following recommendations:

- Family planning services need to be provided to all population subgroups and should be used as a strategy to address maternal and infant mortality problems.

- Family planning information and counseling services need to be strengthened and emphasized at clinics so that clients can make informed decisions about contraceptive methods.

- Service providers need to be continuously trained and updated on the latest contraceptive technology and guidelines for service provision. Training should be reinforced by other mechanisms such as supportive supervision and follow-up home visits.

- Clinic hours need to be modified to reduce the waiting time for clients. Appropriate mechanisms to accommodate women's needs should be developed.

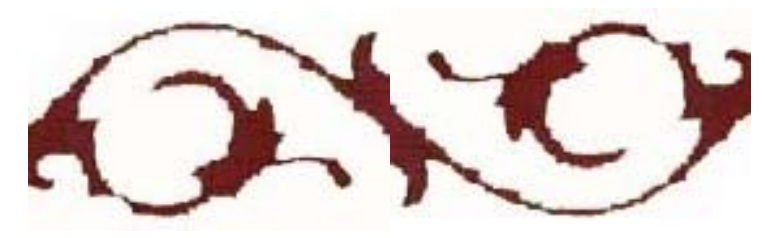




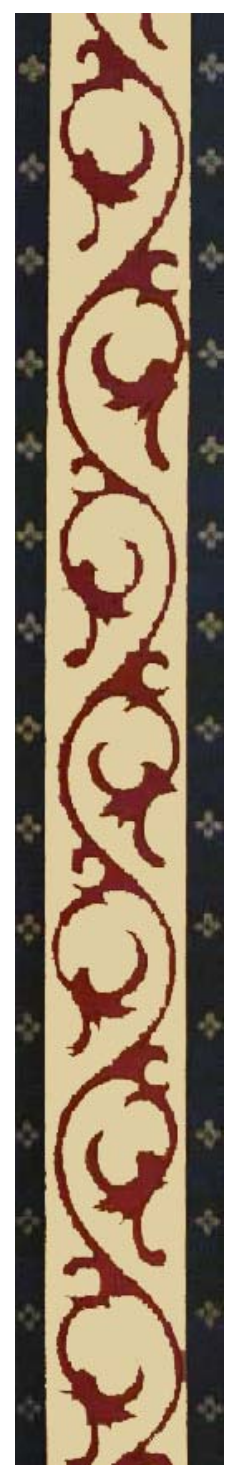

3. Relationship between Early Marriage and the Delivery of Premature Infants in Selected Major Hospitals in the Gaza Strip - Nahed Eid, MPH Candidate

\section{Study Background}

Prematurity is defined as birth before 38 weeks of gestation. It is linked to a range of child health and development problems and is the primary cause of infant mortality in the West Bank and Gaza. International studies indicate that risk of prematurity is higher among pregnant women who are under the age of 18 years. In Palestine 42 percent of marriages involve adolescents who are 17 years old or younger. The median age of first marriage for women is 18 years and 43 percent of first marriages are between first cousins. In addition to infant prematurity, there are a number of other risks associated with pregnancy among women under the age of 18 . These risks include low birth weight (refers to infants who weigh less than 2500 grams), higher possibility of maternal morbidity, malnutrition, abortion, preeclampsia and infant morbidity.

The link between marital age and infant prematurity has not been studied previously in the West Bank or Gaza. This study investigates the association between early marriage and infant prematurity in the Gaza Strip. This is of particular importance since medical professionals' observations and hospital records indicate an increase in the number of premature and low birth weight (LBW) infants since the start of the Intifada.

\section{Study Methodology}

This retrospective study involved the collection of both primary and secondary data. Premature infants (born before 38 weeks or with a birth weight less than 2500 grams) and their mothers who were less than 18 years of age at the time of delivery, were identified through a review of medical records at the intensive care units of Shifa and El Nasser Pediatric Hospitals. The medical records were examined for maternal and demographic data. In addition, a questionnaire was developed to gather primary data on the obstetric health and socio-economic status of mothers of the premature infants.

The study sample includes all premature infants admitted to Shifa and El Nasser Hospitals during 1999. These hospitals serve Gaza City and the middle and northern areas of the 
Gaza Strip. These areas, therefore, constitute the target population of the study. A total of 240 premature infants were identified from El Nasser Hospital and 197 from Shifa Hospital. Initially, the study was designed to include a third hospital - Khanyounis - but due to the instabilities in Gaza, this hospital was dropped from the study.

The study was constrained by a number of factors including inadequacies in the medical records held by participating hospitals and current political instability in the region.

\section{Study Findings}

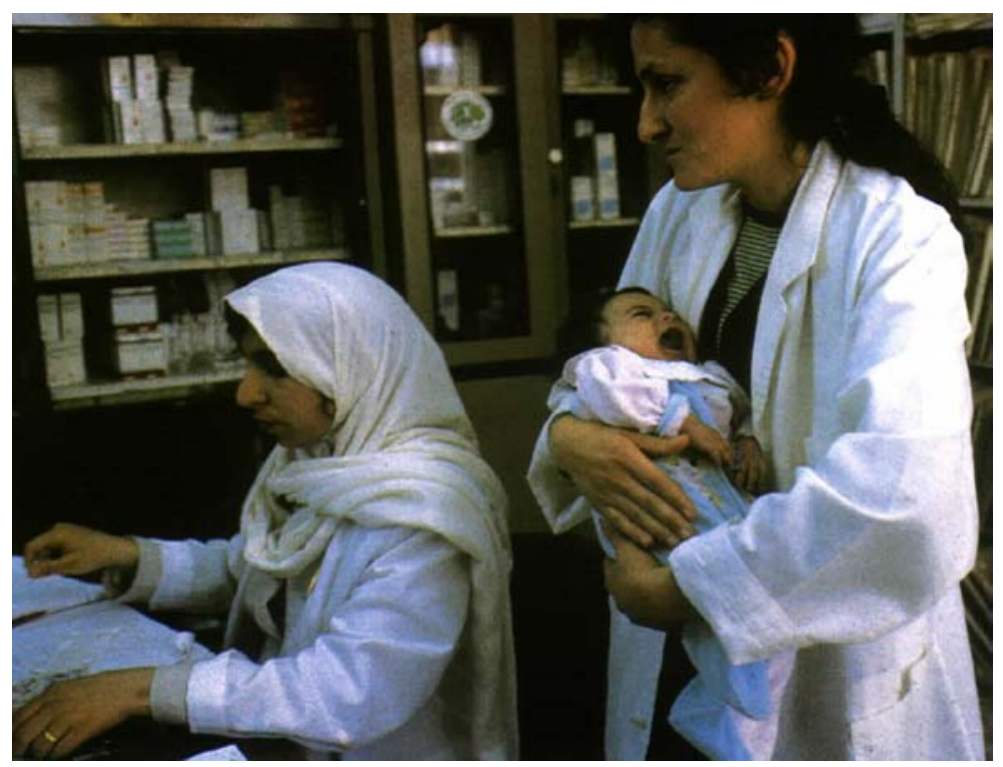

\section{Place of residence}

Of the 240 premature infants included in the study, 51 percent were born to city residents, 29 percent to camp residents and 20 percent to villagers. Although this study does not investigate the association between the place of residence and prevalence of prematurity, this appears significant and deserves further exploration. Socio-economic and nutritional status of families may be contributing factors to premature births.

\section{Sex of premature infants}

The percent distribution of premature infants by sex was 56 percent males and 44 percent females.

Age of mother

About one-half (53\%) of the women at delivery were between the ages of 21-30 years. Seventeen percent were between the ages of 16-20 years and 15.4\% were between the ages of 31-35 years. The remaining women were between $36-40$ years (11.3\%). Only 3 percent of the women were 41 years or above.

Age at marriage

About half $(51.5 \%)$ of the premature babies included in the study were delivered by mothers who were married at 18 years or younger. One third (33\%) of the women were married 
between the ages of 19 - 23 years and 13 percent between the ages of 24 - 28 years. A very small percentage of women were married at 29 years or older. The high percentage of premature deliveries among early-married females ( $<19$ years) was also observed when examined with birth orders up to the fifth child.

\section{Level of education}

On average, mothers participating in the study had 10 years of education. The majority of women $(65.8 \%)$ married while they were in secondary school. Only a small percentage of women (10.4\%) married after completing secondary school. Data on educational levels of fathers and mothers were compared and revealed that women married before the age of 18 years tend to have significantly fewer years of education than men married before the same age. It is important to note, however, that women married between the ages of 19-23 years tend to have more years of education than men married in the same age range. These findings indicate a likely association between marital age and mother's educational level; the earlier a woman married the fewer years of education she was likely to have.

\section{Birth order}

The incidence of premature births was highest among first order births (26\%). About 17 percent of premature births were second order births and only 9 percent of premature births were listed as third order births. This incidence, however, increased significantly again among fourth and sixth order births (18\% and $23 \%$, respectively).

Age of mother at delivery and incidence of premature births

Almost half (about 42\%) of first order children born prematurely were delivered by mothers between the ages of 16 and 20. The incidence of first order children born prematurely, however, decreases as the mother's age increases and drops to only two percent among women aged 36-40 years. However, the drop in risk of delivering a premature infant increases again after women turn 40 .

Mothers married between the ages of 14 and 18 had the largest incidence of premature births. This remains the same through the fifth order child. Women married at or above 24 years face a much smaller risk of delivering a premature infant. For firstborn children, 17.5 percent of premature infants were born to mothers married at 24 years or above while 83 percent were born to mothers married at $<24$ years. 


\section{Conclusions and Recommendations}

This study clearly indicated an association between early marriage and childbearing and premature births in the Gaza Strip. Women married at 18 years or younger were more likely to delivery premature infants than their older counterparts. Furthermore, data from the medical records revealed that women with higher educational levels who married later tended to have lower risks for delivering a premature infant.

Delaying marriage among women may decrease the incidence of premature births and reduce community health care costs. It is also likely to enhance educational opportunities for Palestinian girls.

The following recommendations address the issues and concerns related to early marriage among females:

- Health education programs should emphasize the maternal and infant health hazards associated with early marriage and childbearing among adolescents who are below 18 years of age.

- The potential complications associated with early marriage and childbearing should be incorporated in medical schools' curricula. These issues should also be included in carefully designed messages that target both boys and girls in preparatory and secondary schools.

- In addition to reducing the incidence of early marriage and the risk of premature childbirth, female education should be promoted to empower women to be competent mothers as well as active members of their community.

- Efforts must be made to address gender bias in educational opportunities for youth.

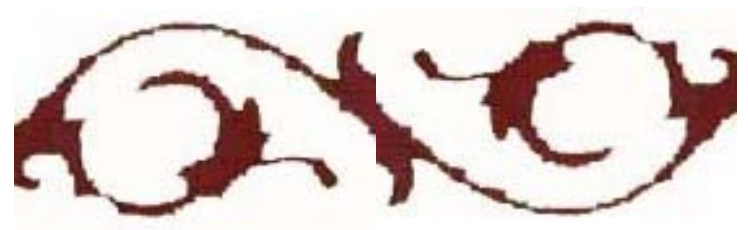




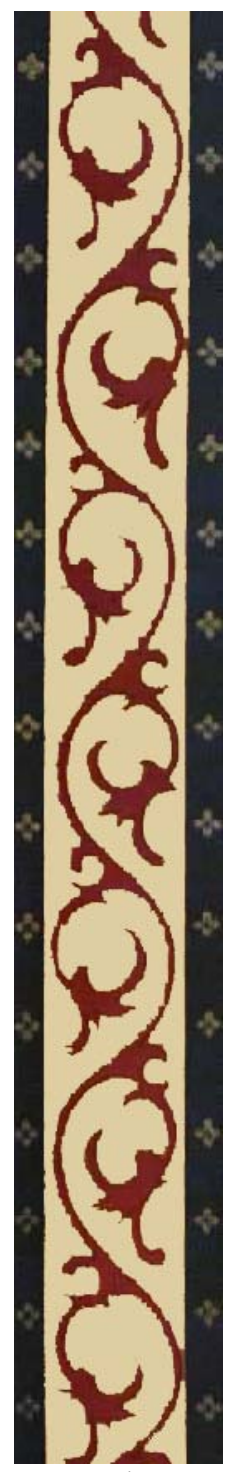

\section{Palestinian Males' Involvement in Family Planning: The Case Study of Al-Nussayrat Camp, Gaza Strip - Mahmoud Okasha, Ph.D., Al Azhar University}

\section{Study Background}

Palestinian society is highly patriarchal. Men have direct influence over all aspects of family life including their wives' reproductive lives. Traditionally, husbands determine at what age their wives begin having children and the number of children they will have. Given the high value attached to sons, Palestinian women often are pressured to continue having children until their extended family are satisfied with the number of sons they have. Nevertheless, despite socio-cultural resistance most men are interested in family planning and have some knowledge about it.

This study aims to determine the knowledge, attitudes and practices of men with regard to reproductive health issues, particularly family planning, in Al-Nussayrat Camp in the Gaza Strip. The primary objective of the study is to determine factors related to male involvement in reproductive health issues. The study findings will be used to develop recommendations that will help promote male involvement in reproductive health issues within the social and cultural context of the Palestinian community.

Al-Nussayrat Camp is one of the most densely populated areas in the world with approximately 57 thousand inhabitants living on approximately 8 square kilometers. The total fertility rate exceeds 5 births and living standards are low. The majority of the population falls below the poverty line. The camp's setting requires inhabitants to rely on services offered by UNRWA such as food rations, health, education, sanitation, housing and employment. The Palestinian Authority and the municipality of the camp offer other services.

The study was carried out during 2001, a year characterized by great violence. In particular, Al-Nussayrat Camp's experience of violence has been significant, which has consequently impacted the study. While acknowledging that care should be taken in interpretation of the data, the principal investigator of the study believes that the results can be considered representative of refugees in Gaza camps. 


\section{Study Methodology}

This descriptive study involved a

population-based sample survey of currently married men living in Al-Nussayrat Camp, Gaza. A sample of 400 married men aged 20-50 living in 400 households in the Al-Nussayrat Camp were selected for interview. The sample was drawn at random through the UNRWA and municipality maps.

Of the 400 men selected for interview, 20 refused to proceed in giving information, and 24 questionnaires were classified as invalid. A total of 356 questionnaires, therefore, were considered valid for data analysis.

\section{Study Findings}

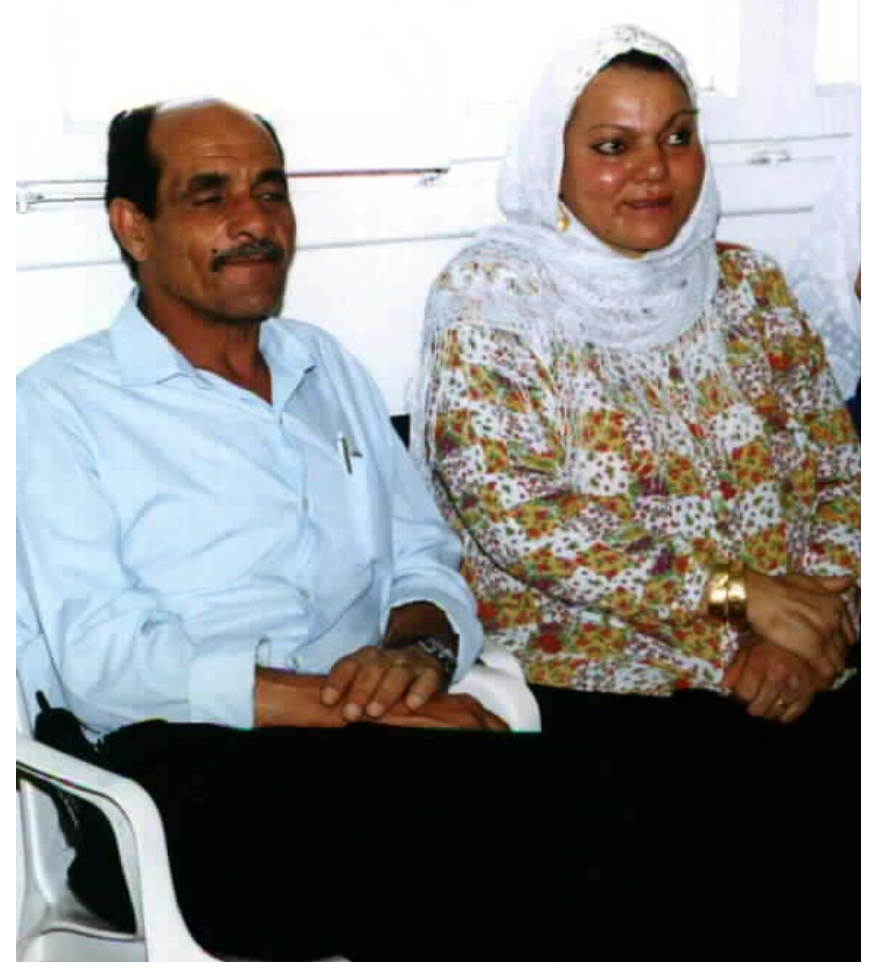

Demographic characteristics of Al-Nussayrat Camp

Consistent with other surveys conducted in the Gaza Strip, there is a higher ratio of men to women in Al-Nussayrat Camp. Males comprise 55 percent of the camp population, with a higher proportion $(57 \%)$ in the age group 0-6 years. The average Al-Nussayrat family is 8.1 persons. The average age of husbands and wives is 39 and 36 years, respectively. Around onehalf of families live in houses that are less than 120 square meters and most of these houses have less than three rooms. The average density (occupation) rate per room is 2.3 persons. Similar conditions exist in other Gaza Strip camps.

Literacy rates are low among the sample population despite the fact that most of the population is below age 50 and children qualify for free education through UNRWA. The average number of years of education for the survey participants was 11.4 years. Their wives had an average of 10.4 years of schools. These averages are higher than the wider population of Gaza, partly because there are very few employment opportunities in Al-Nussayrat Camp and children have no reason to leave school early. 
The majority of male and female residents remain unskilled largely because of the lack of training institutions close to the camp. Only 17 percent of men and just over 10 percent of women receive higher education. Closure of the Israeli borders has contributed to rising unemployment and triggered a significant change in the employment structure of Al-Nussayrat Camp, decreasing the per capita income of married men. Unemployment rates increased from 20 percent to 38 percent during the period of the study.

Marriage and attitudes towards women

The average age of first marriage of Al-Nussayrat residents was 24 years for men and 21 years for women. Educational level has had some impact on the age of first marriage. However, economic and political instability are the most influential factors. Parents prefer their daughters to marry early, most commonly before age 22. The majority of fathers in Al-Nussayrat Camp do allow their daughters some level of freedom in the choice of husbands, however they maintain control over the final decision.

The majority of men at the camp allow women some rights for participation in decisions related to house-keeping, family planning and choosing spouses for their children. However, men tend to exert more control regarding other matters, including those directly related to women, such as whether a woman can work or not. The vast majority of men believe that a woman's role and priority should be caring for her children. Less than 3 percent of men interviewed favored women working. About 81 percent of men believed that it is unacceptable for women to drive cars.

\section{Males' knowledge, attitudes and practices towards family planning}

For the purpose of this study, knowledge of family planning was defined as 'thinking seriously and learning about family planning methods.' By this definition, 56 percent of the study sample was considered knowledgeable of family planning methods. Of these men, however, only about three-fourths $(73.7 \%)$ reported that their wives ever used a family planning method.

IUDs and contraceptive pills are the most widely known methods of family planning among both men and women in the camp. Condoms are not widely known or used by men in the camp, despite the fact that other studies indicate that over half of the women in the camp are aware of this family planning method. 
About 89 percent of the men interviewed had positive attitudes towards family planning. This indicates that the majority of men would be receptive to family planning educational programs. Most men with negative attitudes towards family planning believed it is contrary to their religion. The economic situation was cited as the most common reason for supporting family planning. The majority of men who know about family planning preferred to have one to three children. About one-third also favored family planning as a means of providing better education for their children.

Approximately 41 percent of the study population practices family planning. The difference between the proportion of men who know about family planning and those who reported their wives ever used a method was only 15 percent. This indicates that family planning educational programs can be effective in encouraging men to practice family planning. This is especially important since the influence of women or other family members on practicing family planning is limited. Family planning programs targeting men are therefore essential.

In general, men who do not know about family planning tend to have more children than men who have some knowledge about family planning. However, men's knowledge of family planning appears to have little impact on birth spacing.

\section{Conclusions and Recommendations}

Family planning educational materials must cover the range of different family planning methods, emphasize the advantages of small families, and promote a positive attitude towards women and their health. Programs must aim at changing behavior, and the cultural reservations that previously impeded male responsibility for family planning must be dismantled.

Family planning programs must target male audiences based on specific age groups and educational levels. Television can be the primary medium for dispersing family planning information. This is particularly important since 85 percent of the sample population spends some or most of their spare time watching it. Discussion groups using appropriately trained facilitators are also recommended since they are an effective way of educating target audiences.

In order to gain more insight into the relationship between men's knowledge and their attitudes towards family planning, similar descriptive studies should be conducted in other Palestinian refugee camps, cities and villages.

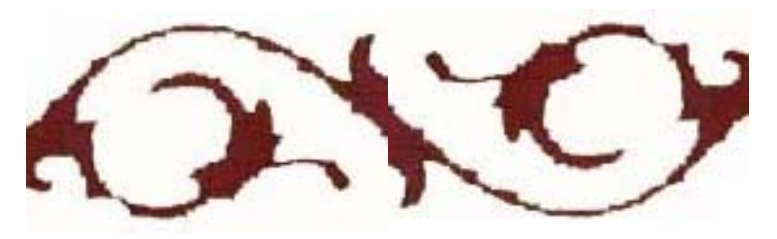




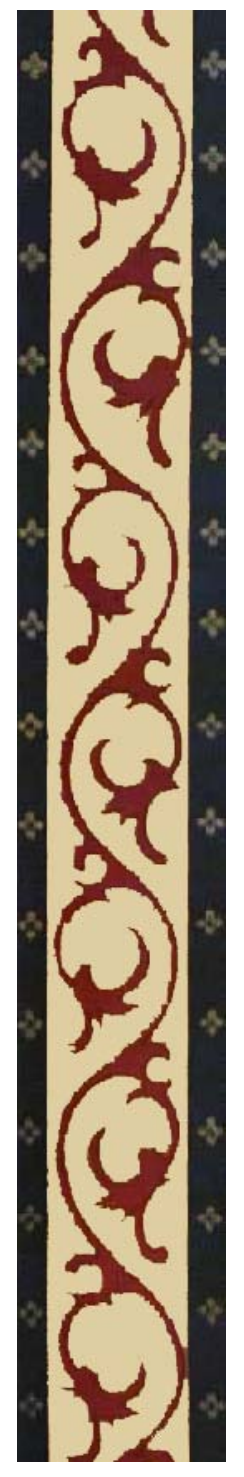

5. Assessment of Factors Affecting Non-compliance for Iron Supplementation among Anemic Pregnant Women in Two Localities in Gaza Strip - Middle and Gaza Provinces - Ahmad Lilly, Private Pharmacist

\section{Study Background}

The World Health Organization (WHO) recommends that women take a daily iron supplementation of up to $120 \mathrm{mg}$ of iron plus $0.25 \mathrm{mcg}$ of folic acid in countries where iron deficiency and anemia are prevalent. Iron supplementation during pregnancy is critical, even for those women who are well nourished, since requirements per day rise from $0.8 \mathrm{mg} /$ day during the first trimester to $6.3 \mathrm{mg} /$ day during the third trimester. Anemia is a common and potentially serious problem during pregnancy. Compliance with iron supplement therapy is therefore crucial to control anemia during pregnancy. Iron deficiency anemia during the first two trimesters of pregnancy is associated with a two-fold increased risk for pre-term delivery and three-fold increased risk for delivering a low-birth weight baby. However, the approach of providing daily supplements of iron in developing countries has had poor results, due in part to doserelated undesirable gastrointestinal side effects and the lack of effective absorption and retention of iron consumed on a daily basis.

The overall aim of this study is to evaluate the effectiveness of the iron supplementation programs that are currently being implemented through $\mathrm{MOH}$ clinics in Gaza. Iron supplements are provided free of charge at $\mathrm{MOH}$ clinics and are offered to clients as part of routine antenatal care services. By assessing the factors associated with compliance for iron supplementation among pregnant women, the study will provide reliable information for improving antenatal care services provided at $\mathrm{MOH}$ and other clinics in Palestine.

\section{Study Methodology}

This non-experimental posttest-only study was conducted at the central MOH clinics in three provinces of Gaza. Data collection relied on three sources of data: medical records, client exit interviews and service provider interviews (5-7 providers per clinic). A total of 300 pregnant women registered at antenatal clinics (100 per clinic) were interviewed after they had received clinic services. The three clinics included Jabalia Clinic (approximately 327 pregnant women attend the clinic for ANC services monthly), Rimal Clinic (approximately 534 pregnant women 
attend the clinic for ANC services monthly) and Sourani Clinic (approximately 353 pregnant women attend the clinic for ANC services monthly). Each pregnant woman selected for the study lived in the same locale of the clinic where she was contacted, had already completed her first trimester of pregnancy, and intended to attend the clinic for future ANC services.

\section{Study Findings}

\section{Socio-demographic data}

The majority of the 300 women interviewed were between 21 and 30 years old (65\%). Most of them (73.3\%) had secondary levels of education and 95.3 percent were housewives. More than half of their husbands (58.7\%) also had secondary levels of education and 64.6 percent were unemployed.

\section{Obstetric factors}

Almost half of the women (47.2\%) had less than four pregnancies, 38.3 percent had 4 to 7 and 14.7 percent had more than 7. About two-thirds (63.3\%) reported having less than 4 live births, 31.7 percent had 4-7 live births and only 5 percent had more than 7 live births. Around 60 percent of the women were in their third trimester of pregnancy - the remaining 40 percent of women were in their second trimester. More than three fourths (77\%) of the women participating in the study visited the clinics monthly for ANC care while 23 percent reported attending the clinics for ANC care either weekly or biweekly. It is important to note that women who were advised to take iron supplements during clinic visits received only 20 pills of the supplement.

\section{Service-related factors}

1. Professional advice to take iron pills during ANC visits: The study findings revealed that only 60 percent of the women interviewed received advice from service providers to take iron supplements during every ANC visit; 38 percent of women reported receiving no advice and 2 percent said they were sometimes advised.

2. Advice not to take iron supplements: Only 18 women from the entire sample were instructed not to take iron supplements. When probed about the source of this advice, 10 of the women said they received this advice through word of mouth. Only two women reported receiving this advice from their service providers. The remaining six women did not answer this question. 
3. Sources for dispensing iron supplement: Of the women who were advised or sometimes advised to take iron pills during clinic visits, 79.4 percent reported that they received their pills from the clinic, 16.8 percent purchased them from a private pharmacy and 3.8 percent from other sources (e.g., NGO clinics).

4. Availability of iron supplements at clinics: 74 percent of the women who were advised to take iron pills during every clinic visit reported that iron supplements were available at their clinic at all times. However, 13.6 percent said that iron pills were only available sometimes. When the same question was posed to service providers, 80 percent responded that iron supplements were always

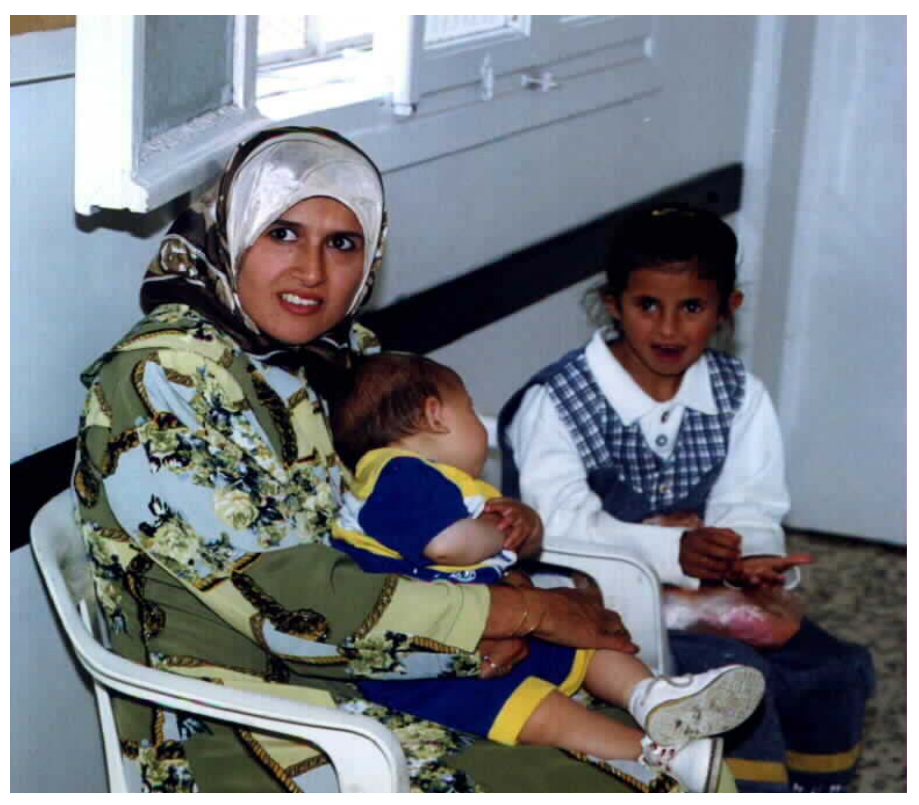
available in their facilities.

5. Client's request for iron pills: The study results revealed that only 13 percent of women interviewed reported asking for iron supplements. About 80 percent of the women reported that they had never asked for iron pills and the remaining 7 percent gave no specific answer. One third of the women (34.4\%) reported fear of side effects as the main reason for not requesting iron pills. The most common reason given by women for not requesting iron pills was that they wanted to seek a doctor's advise first (46.5\%).

6. Association between testing blood hemoglobin and advice for taking iron supplements: Clinic observations confirmed that not every pregnant woman was advised to take iron supplements during ANC visits. However, more importantly, they revealed an association between women's results for blood hemoglobin tests and advice for iron supplementation. Most women were advised to take iron supplements only after they had been questioned about whether their blood hemoglobin had been tested or not, and after it was determined that they were anemic. At the time of interview a total of 60 percent of the women who had reported that they had received blood hemoglobin tests were anemic $(\mathrm{Hg}<11 / \mathrm{dl})$. When asked, 77 percent of these anemic women reported receiving advice about iron supplements 
as compared to only 22 percent of women who were not anemic. The remaining women did not answer the question about hemoglobin tests.

\section{Compliance rates for iron supplementation}

All pregnant women who: a) followed the instructions given to them about taking iron pills, and b) had no excess iron pills (within the period of time the supplement was subscribed) were considered to be compliant. The average rate of compliance at all three clinics in the study was 56.1 percent. Pregnant women from Jabalia Clinic had the highest rate of compliance $(67.3 \%)$. The women from Rimal Clinic had an intermediate compliance rate of 59.7 percent and women from Sourani Clinic had the lowest rate of compliance $(43.1 \%)$.

Among the women who were not compliant, 31.2 percent said they did not care about taking iron pills, 27.3 percent said they did not like the side effects, and 23.3 percent said that they had forgotten to take them. 18.2 percent of the women said they did not like the taste of the iron pill.

\section{Factors related to compliance}

1. Compliance and age: Compliance rates differed from one age group to another. The highest rate of compliance was among pregnant women who were less than 20 years old $(60 \%)$, while the lowest rate of compliance occurred among women who were more than 30 years old (51\%). The compliance rate among 20-30 year olds (the largest age group of the study population) was 57.5 percent.

2. Compliance and education: Although the study results found no statistical significance between compliance and education, the data did indicate an inverse relationship between the two variables - a slight decrease in compliance with iron supplementation with increasing levels of education. About 60 percent of women with 0-6 years of education were complaint as compared to 57.3 percent who had 7-12 years of education and only about 39 percent who had more than 12 years of education.

3. Compliance and obstetric variables: There was no significant association between compliance with iron supplementation and parity, gravidity or gestational age (second or third trimesters).

4. Compliance and advice to take iron supplements: There was no statistical significance associated between this variable and compliance. It is interesting to note, however, that 
the compliance rate among pregnant women who were not advised to take iron supplementation during every visit was about 73 percent.

5. Compliance and availability of supplements in the clinics: There was no statistical significance when availability of pills in the clinic was measured against compliance.

6. Compliance and intervals of clinic visits: The study results showed a statistically significant association between the intervals of visits and compliance with iron supplementation at only one of the three clinics - Sourani Clinic. Clients who visited this clinic every 15 days showed the highest level of compliance (57.1\%). This is an important finding since the clients at Sourani Clinic had the lowest rate of compliance with iron supplementation among the three clinics.

7. Compliance and clarity of instructions: There was no statistical significance in the relationship between clarity of instructions on taking the iron pill and compliance. It is interesting to note that the highest rate of compliance at Rimal Clinic was among pregnant women who moderately understood the instructions for taking iron pills.

8. Compliance and iron supplement palatability: A statistical significant relationship between palatability of the iron pills and compliance was found in all three clinics. 41 percent of pregnant women who did not find the iron pill palatable were compliant.

9. Compliance and blood hemoglobin status: There was no statistical significance in the relationship between testing blood hemoglobin levels or hemoglobin status and compliance at all three clinics.

10. Compliance and self-request for iron pills: Self-request for iron supplementation had no statistical significant effect on compliance.

Pregnant women's knowledge of iron supplementation at ANC clinics

Most $(80 \%)$ of the women interviewed believed that taking iron pills during pregnancy was necessary. However, most women did not know when they should start taking the pills. Most women said that their source of knowledge about the pills was their families $(38.7 \%)$ or professionals $(32.7 \%)$.

Clinic observations and interviews with involved service providers

Clinic observations and interviews with service providers provided the following findings: 
- There were no written guidelines or regulations about iron supplementation during pregnancy at the clinics. ANC physicians only prescribed iron pills to pregnant women who had blood hemoglobin levels below $11 \mathrm{~g} / \mathrm{dl}$ (i.e., anemic women).

- Dispensing procedures for iron supplement prescriptions were poorly carried out. Pregnant women who were prescribed iron pills have to follow a series of procedures to get their prescriptions stamped to receive them free and then have to go to the pharmacies to collect the pills.

- The brand/type of iron supplements provided to pregnant women was not consistent, since stocks in clinics depend on donations received.

- Shortages of iron supplements occur especially towards the end of the month.

Review of clinic forms and other records

The review of clinic records and clinic observations provided the following findings:

1. Reporting of service delivery statistics is inconsistent.

2. The process used by the clinic for ordering and receiving iron supplement pills is cumbersome and needs to be streamlined.

\section{Discussion and Implications}

The results of this study indicated that about 56 percent of pregnant women who received iron supplementation through primary health care facilities comply with taking the pills. This rate of compliance is higher than what other studies have shown. This could be attributed, however, to the small number of iron tablets that were provided to pregnant women ( 20 pills). The distribution of iron supplements to pregnant women in the Gaza Strip is below the WHO recommended level for developing countries.

Other studies indicated that reasons for non-compliance are ignorance about the benefits of iron supplementation, the dark color of feces and the pill's unpleasant odor. When service providers address these concerns women were more compliant. This study was similar to other studies in determining the fact that palatability does affect the rate of compliance. Improving the taste and odor of iron pills will enhance palatability and ultimately improve compliance.

In this study, the number of visits to the ANC clinics did have a statistically significant effect on compliance at one of the three study clinics - Sourani Clinic. This suggests that the regularity of visits may improve client-provider interactions that will in turn lead to improved 
compliance. Service providers can also contribute to improving compliance if they pay more attention to addressing the reasons for non-compliance through follow-up measures.

\section{Conclusion and Recommendations}

Improving client compliance with iron supplements can be achieved through:

1. Providing iron supplements to every pregnant woman attending ANC services.

2. Clarifying the instructions on how to take the pills.

3. Increasing the amount of prescribed iron pills.

4. Raising women's awareness about the benefits of this supplement.

5. Improving the quality of iron supplements purchased to enhance palatability (taste and odor).

6. Providing clients with information on common side effects.

The success of iron supplementation programs depends on high quality service delivery systems that include appropriate instructions and counseling on the use of the supplement and adequate follow-up through effective client-provider interactions. This, in addition to adequate stocks of high quality iron supplements and comprehensive ANC services, may significantly prevent the occurrence of gestational iron deficiency or at least improve its control.

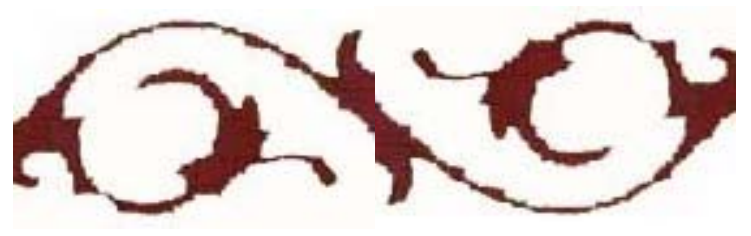




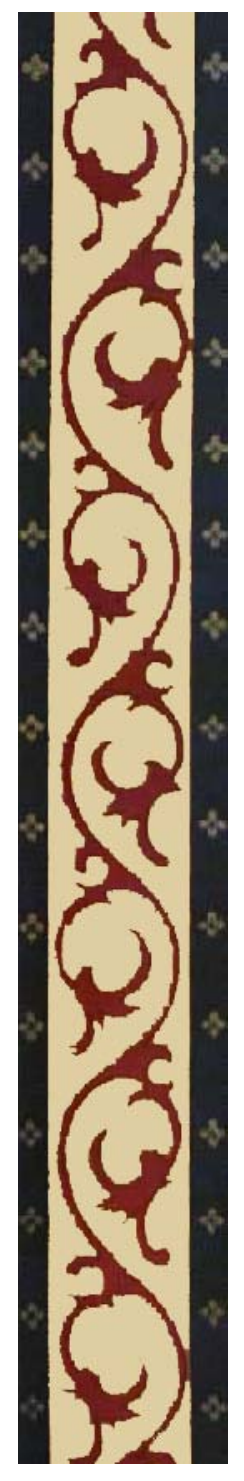

6. Diabetes Mellitus and Pregnancy among Palestinian Women in Gaza: Risk Factors, Complications, Outcome and Quality Improvement Plan - Olfat Sha'at, General Practitioner, MPH Candidate

\section{Study Background}

Diabetes Mellitus (DM) during pregnancy is a widespread health problem. Women with gestational diabetes mellitus (GDM) have an increased chance of developing fetal and maternal complications during pregnancy. Maternal complications include metabolic complications (e.g., hypo and hyperglycemia), chronic complications such as retinopathy, nephropathy and cardiac disease, and obstetric and delivery complications that result in increased rates of cesarian section.

Currently, ANC services provided at maternal and child health $(\mathrm{MCH})$ centers are an integral part of health programs aimed at reducing pregnancy-related morbidity and mortality. Both MOH and UNRWA facilities utilize well-defined guidelines and instructions for the management of pregnant women with diabetes mellitus. Screening pregnant women for diabetes mellitus at UNRWA clinics has been in practice for more than 10 years. However, the diagnosis of diabetes mellitus during pregnancy is still under-reported or misdiagnosed in many communities in Gaza. This occurs even when risk factors enhancing diabetes during pregnancy are highly prevalent.

This cross-sectional study aims to improve the health of women (and their infants) who have been diagnosed with GDM in Palestine. The study compares the knowledge of risk factors, treatment practices, as well as maternal and infant health outcomes among women with diabetes mellitus and women who do not have diabetes mellitus risk factors. The results will provide important facts on the status of diabetes mellitus during pregnancy and the risk factors that may be associated with the prediction of GDM.

\section{Study Methodology}

This cross-sectional case control study was employed to investigate risk factors that are associated with diabetes mellitus during pregnancy and its adverse effects. The study population includes all registered pregnant women both diabetic (pre-gestational, gestational) and normal cases in the southern area of the Gaza Strip who attended MOH and UNRWA primary health care clinics during the period of January 1999 through the end of June 2000. 
A total of six primary health care centers from the southern provinces in the Gaza Strip were selected for the study - Shouhada and "Khan Younis and Rafah" centers (MOH) and Khan Younis, Ma'en, Rafah and Tal Sultan and Shaboura centers (UNRWA). The diabetic cases were randomly matched with two-fold of normal pregnancy cases (control group). The sample size included 84 diabetic pregnant women matched with 168 randomly selected healthy pregnant women. Of the 84 diabetic women who were selected for the study, 24 of them were registered as pre-gestational DM and 60 as GDM during the study period.

Data collection was carried out through structured interviews with the sample population and through a review of maternal health records. Observations of all women's body weight, height and blood pressure were also taken during the study period.

\section{Study Findings}

\section{Estimated prevalence of diabetes mellitus during pregnancy}

The overall prevalence of diabetes mellitus among all pregnant women in the study sites was 0.47 percent during 1999 and early 2000. The nationally reported prevalence of GDM in 1999 and early 2000 was 0.36 percent and 0.29 percent, respectively. This suggests that there may be a low detection of DM during pregnancy and that many cases are not reported. When comparing the two health systems, the prevalence of DM at UNRWA clinics was slightly higher than at $\mathrm{MOH}$ clinics but still below expectations. Comprehensive antenatal and postpartum care services, including proper screening for women, is needed in both health systems.

\section{Socio-economic factors}

Previous studies showed that there was a statistically significant relationship between socio-economic factors and diabetes mellitus during pregnancy, indicating that women from middle and upper income groups with diabetes or high-risk pregnancies accessed prenatal care services early and more regularly than women from low-income families. The findings from this study, however, did not find a statistically significant relationship between the level of education (mother or father), occupation, and residence and GDM. There was also no statistically significant relationship between pregnant women having DM or GDM and consanguineous marriages. 


\section{Risk factors of DM during pregnancy}

Data obtained showed a statistically significant difference between the study group and the control group in relation to history of previous GDM during previous pregnancies. These results suggest that a woman with a history of GDM in a previous pregnancy is at high risk of developing GDM during her next pregnancy.

Four general risk factors were considered to enhance the occurrence of DM in general and GDM specifically. They include: maternal age $\geq 31$ years, positive family history of DM, obesity (BMI $\geq 27$ ), and parity $\geq 6$. There was a significant difference between maternal age in the diabetic and control groups. Older women (age $>30$ ) showed an increased risk of diabetes (odds ratio $=0.2$ ). A positive family history of DM was significantly related to DM during pregnancy. This indicates that pregnant women with a family history of DM are at higher risk of GDM. Obesity was more frequent among diabetic women than among the control group. Results indicate that obese women with $\mathrm{BMI} \geq 27$ were more predisposed to having GDM. The data also indicted that there is a strong association between high parity ( 6 or more children) and predisposition to GDM.

The risk of DM in pregnancy increases with the number of risk factors. All diabetic cases, and GDM subgroup cases in particular, had a high distribution of these risks factors. The chances of women having DM during pregnancy increased greatly with the increased prevalence of risk factors.

\section{Pregnancy complications and DM during pregnancy}

Findings of this study confirmed previous studies that indicated a significant relationship between pregnancy complications and diabetic pregnant women. In general, women with DM were 4.18 times more likely to have complications than women without DM. The number of women reporting one or more complications (anemia, hypertension, preeclampsia, difficult labor and intra-uterine fetal death (IUFD) during the last pregnancy was significantly higher among the study group compared to the control group. Miscarriages, neonatal deaths and cesarean sections were also higher among diabetic women compared to the control group.

- Miscarriages: A history of repeated abortions was more frequent among diabetic women. Women with DM and GDM were exposed to repeated miscarriages 3.97 and 5.86 times more, respectively, than pregnant women without DM. 
- Stillbirths: The same applies for stillbirths. Pregnant women who had a history of DM and GDM were more likely to have experienced a stillbirth as compared to pregnant women without DM or GDM - 6.69 times and 8.5 times, respectively. The difference between the GDM subgroup and the control group by history of previously reported stillbirths was highly statistically significant.

- Low-birth weight babies: Women with DM were at greater risk of delivering LBW babies than women without DM. Pregnant women with DM were 2.13 times more likely to deliver LBW babies than pregnant women without a similar history. An association between insulin intake and treatment of DM was also determined. Insulin intake was 3 times more likely to protect women from having LBW babies.

- Macrosomia: Results indicate that women with DM are at greater risk of delivering macrosomic babies than women without DM. Women with DM and GDM were 6.38 and 5.27 times more likely to deliver macrosomic babies than pregnant women without a similar history.

Knowledge of DM among diabetic pregnant women and access of ANC services

The study results indicate that although the majority of diabetic pregnant women had some knowledge about the various risk factors that can cause complications during pregnancy, they were not aware of the specific risks of DM during pregnancy. Data from medical records also indicated that most diabetic pregnant women registered late for antenatal care services despite having bad obstetric histories. Although this study did not investigate this issue further, previous studies indicated that the reasons for late registration among this subset of women are due to weak counseling and health education about DM during pregnancy and the lack of social support.

\section{Conclusion and Recommendations}

The data obtained from medical records for the study clearly reflected a low detection rate of diabetes during pregnancy. This was attributed to several factors including late screening of pregnant women (24-28 weeks of gestation), infrequent use of risk factor-based screening tools, under-reporting, poor patient compliance with antenatal care services and lack of community health education about DM. 
Comprehensive screening of all pregnant women for gestational diabetes is essential to help decrease both maternal and infant morbidity and mortality. For those women who are high risk or diagnosed with diabetes during pregnancy, close observation, more frequent evaluations and proper medical care are needed to be provided at the clinic level to avoid fetal and maternal complications and to decrease the possibilities of poor pregnancy outcomes.

In addition to the above, health education programs regarding antenatal care and gestational diabetes in particular are crucial for improving the knowledge and awareness of this disease among women and their families.

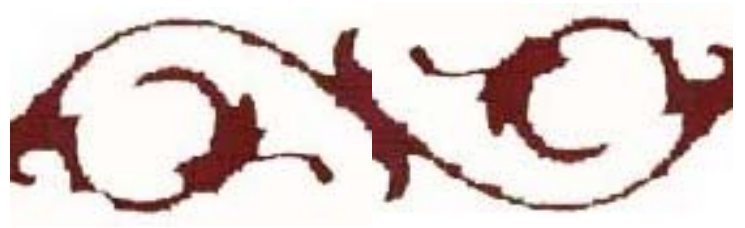




\section{CONCLUSION AND DISSEMINATION OF RESEARCH RESULTS}

The research generated from the Special Studies Program provided important information and data related to reproductive health care issues and concerns in the West Bank and Gaza. The findings from these studies will not only broaden the understanding of population and health issues but will also support future health and population programs, especially in emerging areas of programming such as male involvement.

By supporting innovative research initiatives and providing technical consultations, the Special Studies Program also promoted capacity building among the scholars and researchers in the program. Many of the researchers will be receiving their doctoral or masters' degrees shortly as a result of conducting their studies. Their upgraded skills and experience is seen as an integral part of building a sustainable reproductive health research capacity in the West Bank and Gaza.

Copies of the final reports of all studies were widely disseminated by the individual researchers to program managers, key decision-makers and research experts at several institutions, including the $\mathrm{MOH}$, NGOs, universities and relevant $\mathrm{UN}$ agencies. Many of the researchers also plan to present the findings of their studies through dissemination meetings and upcoming conferences. A large-scale dissemination meeting for the overall Special Studies Program will also be programmed at the end of the Pilot Health Project in December 2001. This dissemination meeting will include audiences of reproductive health experts, program managers and key decision-makers from the $\mathrm{MOH}$, UNRWA, NGOs and other institutions that are in a position to actively support or act upon the conclusions and recommendations from the research studies. 